\title{
Sistem Informasi Administrasi SDIT Mauritaniyyah
}

\author{
Muhammad Saputra ${ }^{1}$, Muhammad Alan Wahyu Andrian², Rezkiyana Hikmah ${ }^{3}$ \\ 1,2,3 Universitas Indraprasta PGRI \\ Jl. Raya Tengah No.80, RT.6/RW.1, Kel. Gedong, Kec. Pasar Rebo \\ Kota Jakarta Timur,Daerah Khusus Ibukota Jakarta 13760 \\ 1 anvikalputra@gmail.com \\ ${ }^{2}$ Muhaland.unindra@gmail.com \\ ${ }_{3}^{3}$ rezkiyana.hikmah0303@gmail.com
}

\begin{abstract}
Abstrak - Sekolah Dasar Islam Terpadu Mauritaniyyah ditengah - tengah kaum muslimin menjawab tentang pentingnya pendidikan islam. Mengkokohkan serta menebalkan keimanan, memberikan pemahaman ajaran islam yang baik dan benar sesuai dengan pemahaman Ahlul Sunnah Wal Jama'ah. Tujuan dari penelitian adalah untuk membuat sistem administrasi yang mempermudah dan mempercepat kinerja staff admin. Metode yang dilakukan dalam merancang sistem pengolahan data administrasi posyandu adalah metode analisis dan perancangan sistem berorientasi objek (Object Oriented Modelling) menggunakan tools pengembangan system Unified Modelling Language (UML). Pengujian yang dilakukan adalah pengujian validasi, pengujian kuesioner dan pengujian aplikasi. Hasil penelitian sistem informasi administrasi sekolah dapat membantu admin memproses pengolahan data dan laporan pada SDIT Mauritaniyyah menjadi cepat, dan akurat. Setelah penulis merancang dan menganalisa sistem administrasi, maka penulis dapat menarik simpulan bahwa administrasi itu tidak selamanya berkembang dengan program ini. Membangun aplikasi administrasi ini sangat membutuhkan waktu agar hasilnya dapat memuaskan.
\end{abstract}

Kata Kunci: Administrasi, Sekolah, Unfied Modelling Language, Object Oriented Modelling.

Abstract - Mauritaniyyah Islamic Primary School in the midst of the Muslims answered about the importance of Islamic education. Strengthen and thicken faith, provide a good and correct understanding of Islamic teachings in accordance with the understanding of Ahlul Sunnah Wal Jama'ah. The purpose of this research is to create an administrative system that simplifies and speeds up the performance of admin staff. The method used in designing the posyandu administrative data processing system is the method of analysis and design of an object-oriented system (Object Oriented Modeling) using the Unified Modeling Language (UML) system development tools. The tests carried out are validation testing, questionnaire testing and application testing. The results of research on school administration information systems can help admins process data processing and reports at SDIT Mauritaniyyah to be fast, and accurate. After the authors design and analyze the administrative system, the authors can draw the conclusion that administration does not always develop with this program. Building this administrative application really takes time so that the results can be satisfactory. Keywords: Administration, School, Unfied Modelling Language,Object Oriented Modelling

\section{Pendahuluan}

Pendidikan sekolah yang begitu penting dikalangan masyarakat untuk saat ini menjadi sorotan utama dalam menentukan pendidikan yang berkualitas. Oleh karena itu, penggunaan teknologi dalam menunjang kegiatan sekolah sangat diperhatikan dalam sistem administrasi transaksi. Hal ini didapatkan beberapa sekolah yang masih melakukan transaksi administrasi dengan sistem manual. Hal tersebut dapat menyebabkan banyak sekali kekurangan yang terdapat pada administrasi sekolah dalam menjadikan sekolah untuk memperbaiki management administrasi yang baik, rapih, dan teratur. Memperbaiki management administrasi sekolah sangat penting agar masalah yang terjadi dalam memasukkan data, memproses data, melakukan transaksi, membuat laporan dengan baik dan benar. Persoalan yang terdapat di SDIT Mauritaniyyah dalam pendataan siswa, kelas, tahun pelajaran, buku, dan ujian yang belum terstruktur dan redundasi data. Pada proses transaksi masih manual dengan menggunakan nota dan tidak tersimpan dengan baik. Laporan hasil pendataan dan laporan transaksi masih kurang sinkron dalam penyimpannya data, sehingga membutuhkan waktu yang lama dalam mencari dan mencetak laporan.

Sistem administrasi di SDIT Mauritaniyyah belum terkomputerisasi, sehingga menyebabkan proses pendataan di SDIT Mauritaniyyah belum tersetruktur dan redunsansi data. Oleh karena itu, sistem administrasi di SDIT itu perlu membuat sebuah aplikasi dimana dalam satu form terdapat Input dan table hasil Inputan, selanjutnya data disimpan ke dalam database MySQL. Proses transaksi yang dilakukan masih menggunakan Microsoft Excel, sehingga perlu dibuat dengan bahasa pemrograman Java structural. 
Berdasarkan uraian di atas, diharapkan dengan aplikasi yang dirancang sesuai kebutuhan SDIT Mauritaniyyah dapat memudahkan admin bekerja dengan baik dan rapih. Oleh karena itu, penelitian ini berjudul adalah "Sistem Informasi Administrasi SDIT Mauritaniyyah Berbasis Java".

\section{Tinjauan Pustaka}

2.1. Sistem

Sistem adalah suatu jaringan kerja dari prosedur yang saling berhubungan, berkumpul bersama-sama untuk melakukan suatu kegiatan atau untuk menyelesaikan suatu sasaran tertentu[1]. Sistem menjelaskan bahwa data yang telah dikelola dan diproses untuk memberikan arti dan memperbaiki proses pengambilan keputusan[2]. Sistem juga dapat diartikan sebagai kesatuan secara konseptual atau fisik yang terdiri dari bagian-bagian dalam keadaan saling tergantung satu sama lainnya [3].

2.2. Informasi

Informasi adalah data yang telah diolah menjadi bentuk yang lebih berarti dan berguna bagi penerimanya untuk mengambil keputusan masa kini maupun yang akan datang[4]. Informasi juga dapat didefinisikan sebagai hasil dari pengolahan data dalam suatu bentuk yang lebih berguna dan lebih berarti bagi penerimanya yang menggambarkan suatu kejadian-kejadian (event) yang nyata (fact) yang digunakan untuk pengambilan keputusan[5]. Hasil dari pengolahan data yang memberikan arti dan manfaat[6].

2.3. Administrasi

Administrasi adalah usaha dan kegiatan yang berkaitan dengan penyelenggaraan kebijakan untuk mencapai tujuan. Istilah administrasi diambil dari kata "ad" dan "ministro". Ad mempunyai arti "kepada" dan ministro berarti "melayani" sehinggaadministrasi diartikan sebagai pelayanan atau pengabdian terhadapsubjek tertentu. Selain itu, kata administrasi juga berasal dari bahasa Belanda, yaitu administrate yang artinya kegiatan penyusunan dan pencatatan. Kegiatan ini mencakup kegiatan tulis-menulis, mengirim danmenyimpan keterangan, dan dikaitkan pula dengan aktivitas administrasiperkantoran yang hanya merupakan salah satu bidang dari aktivitasadministrasi yang sebenarnya[7].

Administrasi dapat diarti sbahwa 'Kata ad dalam administrasi mempunyai arti yang sama dengan kata to dalam Bahasa Inggris yang berarti "ke" atau "kepada". Kata ministrare sama artinya dengan kata to serve atau to conduct yang berarti "melayani", "membantu", atau "mengarahkan". Dalam bahasa Inggris, to administer berarti pula mengatur, memelihara (to look after), dan mengarahkan. Administrasi merupakan kegiatan atau usaha untuk membantu, melayani, mengarahkan, atau mengatur semua kegiatan di dalam mencapai suatu tujuan. Administrasi sebagai suatu proses organisasi dan individu yang berhubungan dengan pelaksanaan visi dan misi suatu institusi atau lembaga tertentu[8].

\section{4. $M y S Q L$}

MySQL adalah sebuah perangkat lunak sistem manajemen basis data SQL (Database Management System) atau DBMS yang multithread, multi- user, dengan sekitar 6 juta instalasi di seluruh dunia[10]. Perintah MySQL dibagi dalam 2 kategori sesuai fungsinya yaitu DDL (Data Definition Language) dan DML (Data Manipulation Language).

2.5. Java

Java adalah bahasa pemrograman yang dapat dijalankan di berbagai komputer termasuk telpon genggam[11]. Java berdiri di atas sebuah mesin interpreter yang diberi nama Java Virtual Machine (JVM). $J V M$ inilah yang akan membaca bytecode dalam file class dari suatu program sebagai representasi langsung program yang berisi bahasa mesin. Oleh karena itu, bahasa Java disebut bahasa pemrograman portable karena dapat dijalankan pada berbagai sistem operasi, asalkan pada sistem operasi tersebut terdapat JVM.

2.6. NetBeans

Netbeans merupakan sebuah aplikasi Integrated Development Environment (IDE) yang berbasiskan Java dari Sun Microsystems yang berjalan di atas swing. Pengembangan NetBeans diawali dari Xelfi, sebuah proyek tahun 1997 di bawah bimbingan Fakultas Matematika dan Fisika, Universitas Charles Praha, sebuah perusahaan kemudian dibentuk untuk proyek tersebut dan menghasilkan versi komersial NetBeans IDE hingga kemudian dibeli oleh Sun Microsystem pada tahun 1999. Sun Microsystem kemudian menjadikan NetBeans open source pada bulan Juni tahun 2000, sejak itu komunitas NetBeans terus berkembang.

\subsection{XAMPP}

XAMPP adalah sebuah software web server apache yang didalamnya sudah tersedia database $M y S Q L$ dan support PHP Pemrograman. XAMPP merupakan pengembangan dari LAMP (Linux Apache, MySQL, PHP and Perl)[3]. XAMPP ini merupakan project non-profit yang dikembangkan oleh Apache Friends yang didirikan Kai 'Oswalad' Seidler dan Kay Vogelgesang pada tahun 2002, project mereka ini bertujuan mempromosikan pengunaan Apache web server. 


\subsection{UML (Unified Modeling Language)}

Unified Modeling Language adalah salah satu standar bahasa yang banyak digunakan di dunia industri untuk mendefinisikan requirement, membuat analisis \& desain, serta menggambarkan arsitektur dalam pemrograman berorentasi objek[1]. Pemodelan sesungguhnya digunakan untuk penyederhanaan permasalahan-permasalahan yang kompleks sedemikian rupa sehingga lebih mudah dipelajari dan dipahami[14].

\section{Metode Penelitian}

Penelitian ini menggunakan metode SDLC (System Develpoment Life Cycle). SDLC adalah proses pembuatan dan pengubahan sistem serta model dan metodologi yang digunakan untuk mengembangkan sebuah sistem. SDLC juga merupakan pola yang diambil untuk mengembangkan sistem perangkat lunak, yang terdiri dari tahap-tahap: rekayasa sistem, analisis (analysis), desain (design), implementasi (implementation), uji coba (testing) dan pengelolaan (maintenance)[11]. Model SDLC yang dipakai dalam penelitian ini adalah model waterfall. Pengumpulan data dilakukan dengan 3 cara yaitu :

3.1. Metode Lapangan

Obeservasi dilakukan dengan cara mendatangi langsung dan survey terhadap objek secara langsung untuk mendapatkan informasi dasar yang dibutuhkan objek yang diteliti. Peneliti melakukan observasi mengenai proses pendataan siswa, kelas, tahun pelajaran di dalam ruang administrasi.

Wawancara dilakukan dengan cara langsung dan meminta penjelasan secara rinci kepada Kepala Sekolah dan Staff Administrasi SDIT Mauritaniyyah pada sumber-sumber yang terkait. Wawancara dibutuhkan beberapa kali waktu pertemuan agar data yang didapat benar.

Dokumtasi diperoleh dengan cara melihat dan mencatat data yang terdapat pada dokumen atau arsip SDIT Mauritaniyyah. Proses dokumentasi dilakukakn dengan teliti karena khawatir terjadi kesalahan.

3.2. Studi Kepustakaan

Pengumpulan data dan informasi dari kutipan-kutipan buku, perpustakaan Universitas Indraprasta PGRI yaitu skripsi-skripsi yang berhubungan dengan sistem administrasi sekolah dan metode $U M L$, dan catatancatatan perkuliahan hasil laporan serta bahan lainnya yang berkaitan dengan pembuatan laporan penelitian. Bahan-bahan dari teori yang dapat dijadikan sebagai landasan untuk menganalisa masalah yang dikemukakan dalam penelitian.

\section{Hasil dan Pembahasan}

Aturan sistem pengolahan data SDIT Mauritaniyyah sebagai berikut :

4.1. Data Siswa, Kelas, Tahun Pelajaran, dan Buku

Data ini akan di input dan diolah oleh bagian administrasi sekolah. Data tersebut akan diperlukan saat proses transaksi pembayaran SPP, pembayaran buku, dan pembayaran lainnya.

4.2. Transaksi Pembayaran SPP

Wali Murid melakukan transaksi pembayaran SPP kepada admin, kemudian bagian admin memprosesnya. 4.3. Transaksi Buku

Wali Murid melakukan transaksi pembayaran buku kepada admin, kemudian bagian admin memprosesnya. 4.4. Data Laporan

Pimpinan yayasan dapat melihat dan menerima laporan kegiatan dari admin.

Berikut ini adalah tampilan dari perancangan sistem pengolahan data administrasi pada SDIT Mauritaniyyah. Use Case Diagram 


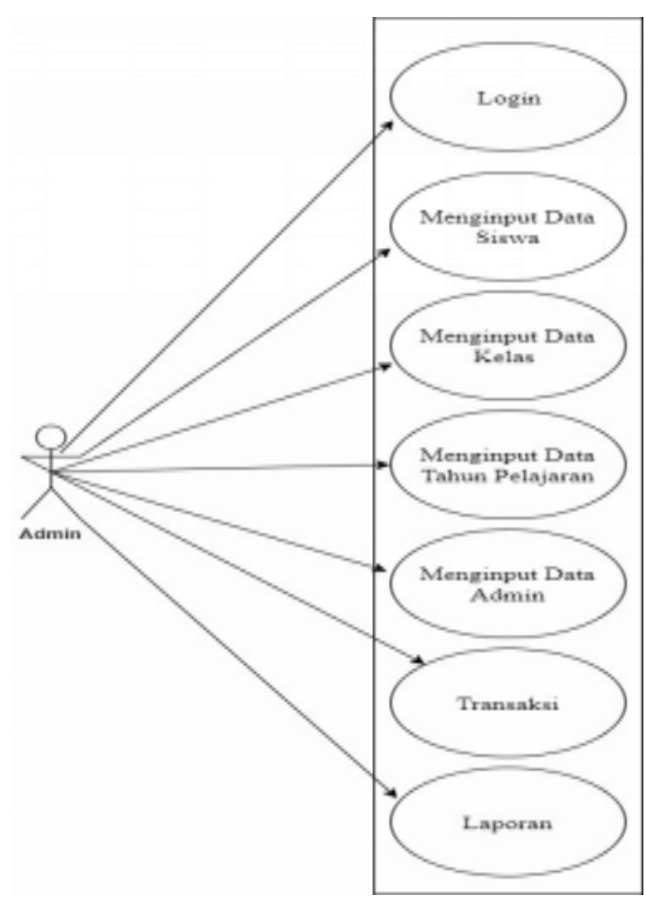

Gambar 1. Use Case Diagram

\section{Login}

Menu login digunakan sebagai kata kunci sebelum kita memasuki program utama agar tidak sembarang orang dapat mengakses program ini sehingga kerahasiaannya tetap terjaga dengan baik.

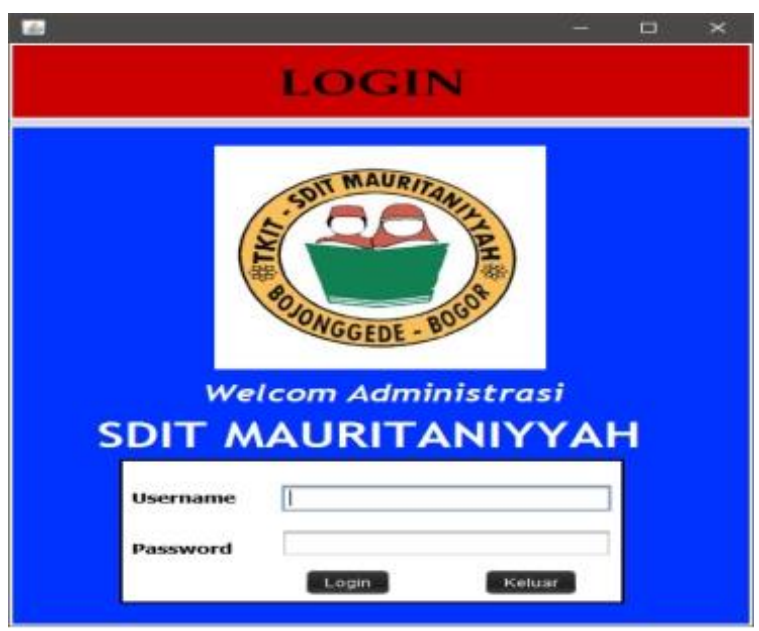

Gambar 2. Login

\section{Menu Utama}

Menu yang terdapat dalam tampilan ini diantaranya : menu master, menu transaksi, menu laporan, menu user, menu tentang aplikasi dan menu keluar. 


\section{Master}

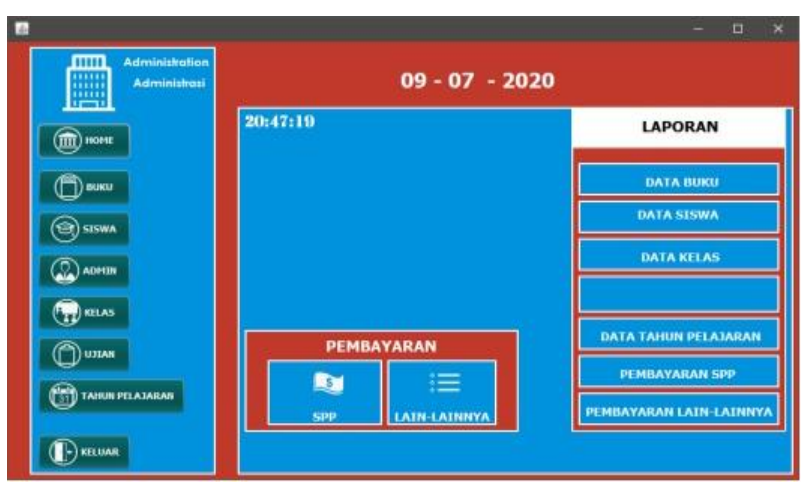

Gambar 3. Menu Utama

Menu master digunakan untuk menginput data yang diperlukan dalam proses transaksi.

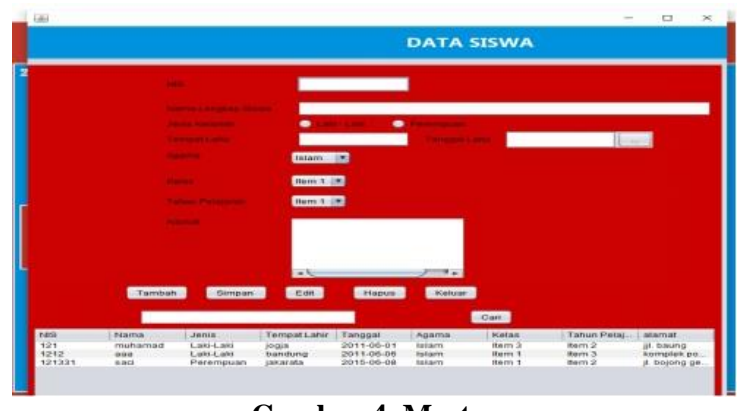

\section{Gambar 4. Master}

\section{Transaksi}

Menu transaksi digunakan untuk menginput data transaksi agar mendapatkan laporan yang atau informasi yang akurat dan sistematis.

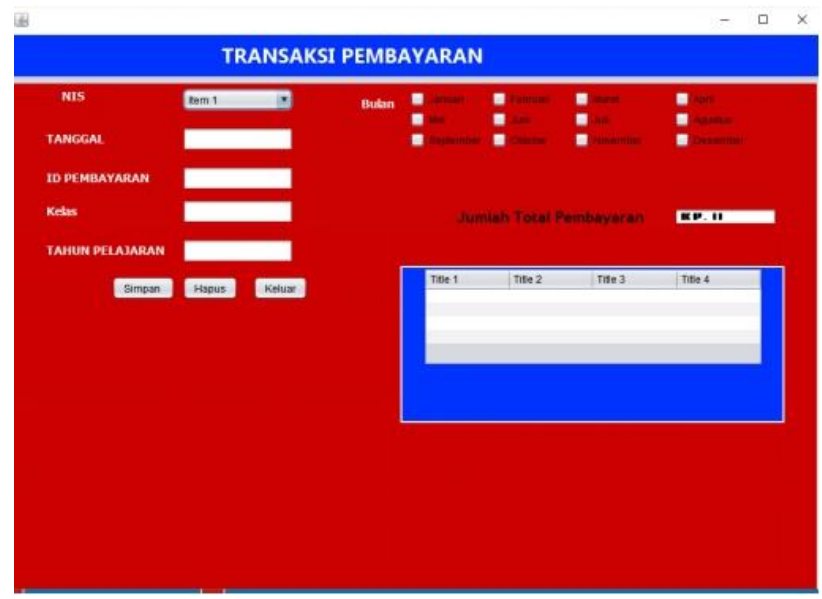

Gambar 5. Menu Transaksi

\section{Laporan}

Menu laporan digunakan untuk mencetak data transaksi yang sudah di proses. 


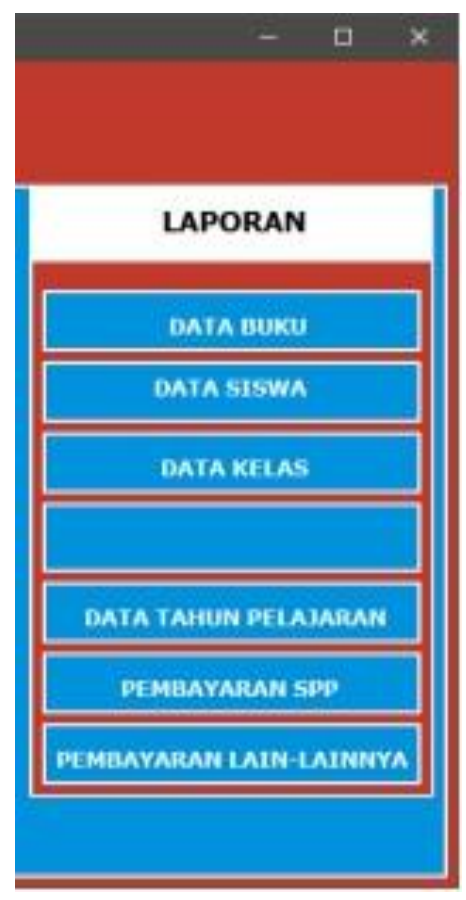

Gambar 6. Menu Laporan

\section{Cetak Laporan}
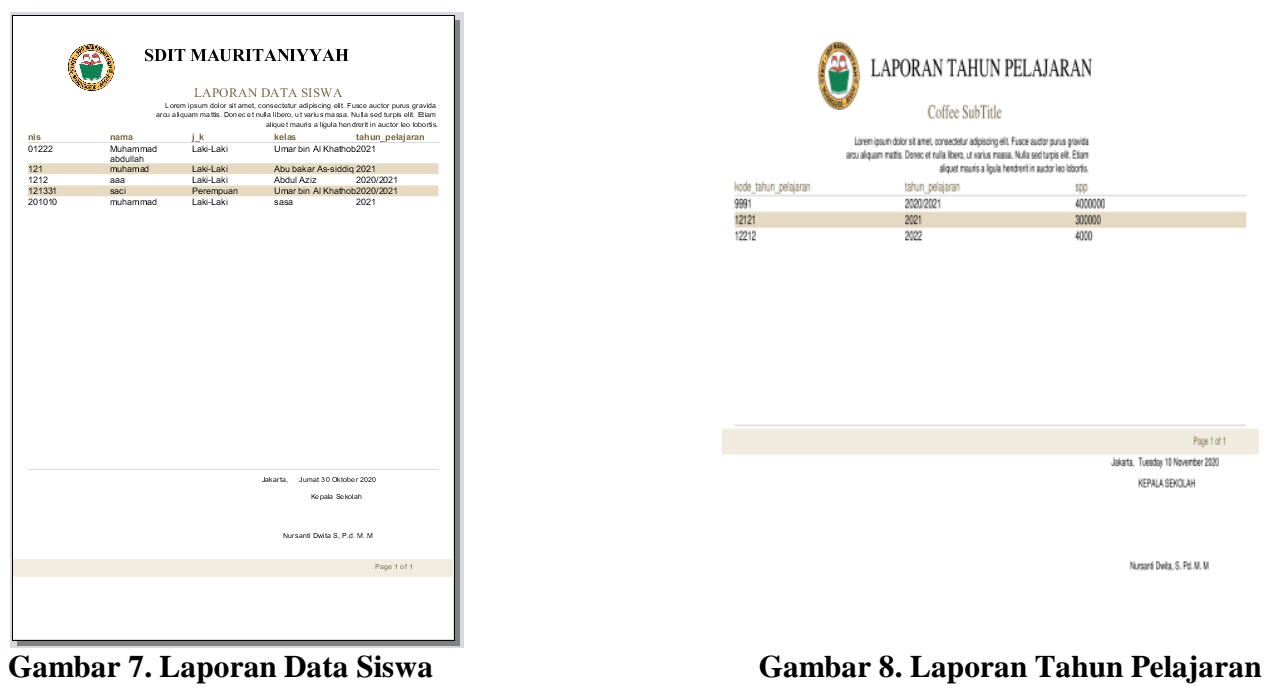

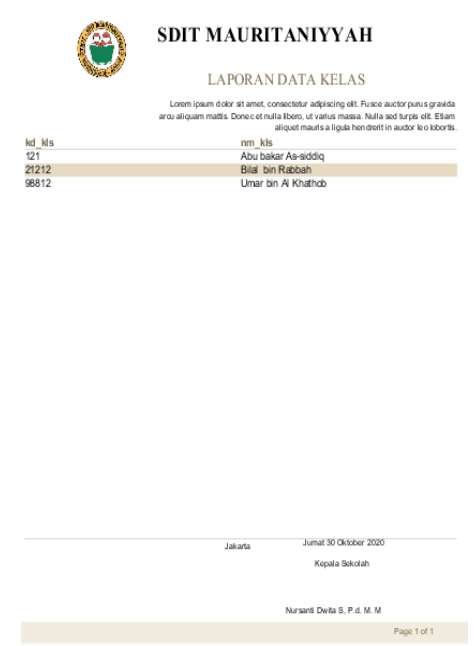

Gambar 9. Laporan Data Kelas

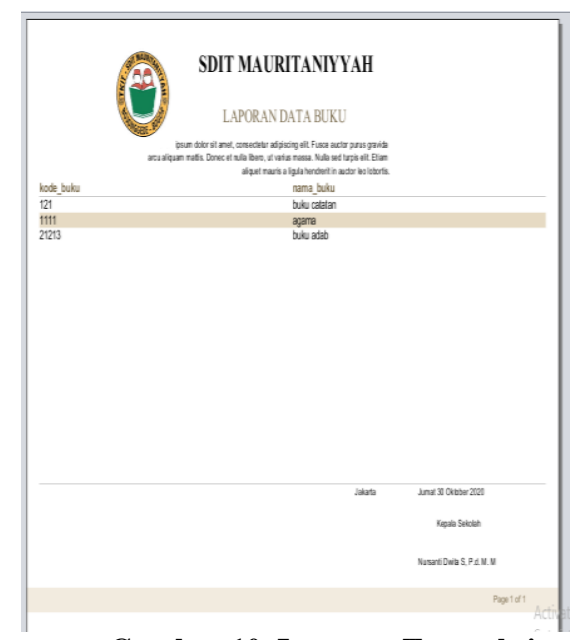

Gambar 10. Laporan Transaksi

\section{Kesimpulan}

Hasil dari penelitian ini menunjukkan rancangan sistem informasi administrasi di SDIT Mauritaniyyah dapat meminimalisir proses pendataan yang tidak terstruktur pada data siswa, kelas, tahun pelajaran, buku dan ujian. Sistem pencatatan transaksi dapat terkomputerisasi dengan baik menggunakan aplikasi NetBeans dengan bahasa pemrograman Java pada sistem administrasi di SDIT Mauritaniyyah. Perancangan sistem informasi administrasi SDIT Mauritaniyyah berbasis Java menghindari dari penumpukan data. Rancangan sistem administrasi SDIT Mauritaniyyah yang penulis buat sebagai penunjang admin untuk mengefisienkan waktu dan keakuratan data dalam membuat laporan.

\section{Daftar Pustaka}

[1] A. Kohar, M. N. W. N. Witama, and R. A. Sumarni, "Perancangan Sistem Pengolahan Data Jamaah Haji Dan Umroh Pada PT. Dream Tours And Travel," J. Nas. Komputasi dan Teknol. Inf., vol. 3, no. 3, pp. 305-313, 2020.

[2] L. Situmorang and J. R. Sagala, "Sistem Pendukung Keputusan Pemilihan Tentor Terbaik Dengan Metode Technique For Order Preference By Similarity To Ideal Solution (Topsis)," J. Nas. Komputasi dan Teknol. Inf., vol. 3, no. 3, pp. 209-214, 2020.

[3] M. R. Utomo, M. N. Witama, and R. A. Sumarni, "Perancangan Sistem Informasi Pendaftaran Siswa Baru Berbasis Java Dekstop Pada Madrasah Ibtidaiyah Al-Ihsan," J. Nas. Komputasi dan Teknol. Inf., vol. 3, no. 3, pp. 323-329, 2020.

[4] Baihaqi, R. Islamadina, and D. Alfairus, "Sistem Informasi Persediaan Barang Habis Pakai Berbasis SMS Gateway Pada Kantor Camat Seulimuem Kabupaten Aceh Besar," J. Nas. Komputasi dan Teknol. Inf., vol. 1, no. 1, pp. 10-16, 2018.

[5] M. Munawir and E. Erdiwansyah, "Perancangan Portal Informasi Gampong pada Gampong Lambeugak Kecamatan Kuta Cot Glie Aceh Besar," J. Nas. Komputasi dan Teknol. Inf., vol. 1, no. 2, 2018.

[6] S. M. Hutabarat and A. Sindar, "Data Mining Penjualan Suku Cadang Sepeda Motor Menggunakan Algoritma K-Means," J. Nas. Komputasi dan Teknol. Inf., vol. 2, no. 2, pp. 126-132, 2019.

[7] D. Satria, T. Hidayat, M. A. Hidayat, and Z. Zakaria, "Application of SMS Gateway on Attendance Detection Systems using RFID," J. Nas. Komputasi dan Teknol. Inf., vol. 1, no. 2, 2018.

[8] M. Munawir and K. Karmila, "Pengembangan Aplikasi Pengusulanpembimbing Tugas Akhir Secara Online Pada Fakultas Teknik Universitas Serambi Mekkah," J. Nas. Komputasi dan Teknol. Inf., vol. 1, no. $1,2018$.

[9] I. Aprilia, A. D. Puspita, I. D. Kumalagusti, Herlina, and S. Ayu, "Sistem Informasi Akuntansi Pendapatan Siklus keuangan," J. Chem. Inf. Model., vol. 2, no. 1, p. 15, 2019.

[10] S. Deni Gunawan, Dwi Puji Hastuti, Ria Andriani, "Sistem Informasi Penjualan Berbasis Web Pada Restoran Caki Cake Karawang,” J. AKRAB JUARA, vol. 2018, no. 1-10, pp. 1-18, 2018.

[11] N. R. Lase and F. Riandari, "Perancangan Aplikasi Prediksi Jumlah Pendaftar Siswa Baru Dengan Metode Regresi Linier (Studi Kasus: SMA RK Deli Murni Bandar Baru)," J. Nas. Komputasi dan Teknol. Inf., vol. 3, no. 3, pp. 330-334, 2020. 